\title{
A Proposal for a National Institute of Library Science
}

It is an interesting, if depressing, paradox that the library profession whose raison d'être is the conservation of knowledge permits so much of its own cumulative experience to slip away unrecorded and without possibility of recall. I refer to the fact that as yet we have not utilized the medium of television to preserve important aspects of the careers of a relatively small number of leaders of the profession who have played crucial roles in the development of library services at all levels over the past three to four decades. These are the individuals whose intellectual energies, personal charisma, and dedication have moved libraries in the direction of network for the acquisition, bibliographic control, and dissemination of knowledge on a global scale.

The published research of this group is, of course, available. At its best, it represents their cumulative experiences refined and purified through a critical dialectic. At its worst, it is similar to much of library literature; descriptive, pedantic, and dull. And herein lies another paradox. Although library literature on the whole is deadening, many of the people who produce it and the issues it reflects are exciting and intellectually challenging. Modern technology, specifically television, provides the means of recording what the literature often only hints at-or misses completely-the personalities of the leadership of the profession and the atmospherics of the professional environment in which they have labored.

The burden of this editorial is to make a plea for the establishment of a National Institute for Library Science whose sole function would be to use the medium of television to preserve that which is now being lost: the unique and creative personalities of the profession. Taped seminars analogous to those moderated by David Susskind might be a fruitful approach. No formal speeches, lectures, no bull sessions, but true seminars bringing together the leaders of the profession and moderated in such a manner that the focus is continually on the historical, immediate, or future problems and issues facing the profession.

The possibilities for individual seminars are legion, but one in particular leaps to the forefront-an exchange of ideas between Seymour Lubetsky and several of the people whose views carried the day in the writing of the Anglo-American Rules for Descriptive Cataloging. What a shame it is that death has made impossible a seminar featuring Joe Wheeler and the opponents of cataloging-in-source.

A program such as this sustained over a long period would result in several contributions to librarianship. First, by making the video 
tapes, or kinescope copies, available to the library schools, all instead of a lucky few enrolled in our graduate programs could be exposed to the personalities of some of the best of our practitioners and theorists and witness important issues discussed at the highest possible level. Second, if used properly, the taped programs could substantially reduce the number of large lecture classes now offered by the library schools and in so doing help create an environment which more closely approximates graduate education in other disciplines. Finally, the taped seminars would serve as an additional link between past, present, and future generations of librarians, preserving the unwritten thoughts, the unwritten flights of imagination, the humor and the tenaciously held diagreements in principle between men and women of good will engaged in a crucial enterprise.

Funding for a National Institute for Library Science could come from a number of sources, foundations, professional associations, or the Council on Library Resources. Ideally, however, it would make sense for the major portion of the funding to come from the library schools themselves whose programs would be so immeasurably enriched by the institute's activities. A yearly contribution of $\$ 2,000$ from each of the accredited schools would produce approximately $\$ 100,000$ and would provide each of them with the services of an ever-expanding adjunct faculty representing the leadership of the profession for a fraction of the annual salary of a single assistant professor.

H. William AxFord

University Librarian

Arizona State University 